\title{
USF1 gene polymorphisms may associate with the efficacy and safety of chemo- therapy based on paclitaxel and prognosis in the treatment of ovarian cancer
}

\author{
H. YE ${ }^{*, \star}$, X.J. LIU ${ }^{*}$, Y. HUI, Y.H. LIANG, C.H. LI, Q. WAN \\ Department of Obstetrics and Gynecology, The First Clinical Medical College of China Three Gorges University, Yichang 443003, China \\ ${ }^{*}$ Correspondence: yehong_YH77@163.com \\ "Contributed equally to this work.
}

Received March 22, 2017/ Accepted May 29, 2017

\begin{abstract}
This study was supposed to investigate the correlation between the functional single nucleotide polymorphisms (SNPs) (rs2516839 and rs3737787) in USF1 gene and the efficacy and safety of paclitaxel-based chemotherapy and prognosis in the treatment of ovarian cancer (OC). In total $100 \mathrm{OC}$ patients were selected and divided into the sensitive group and the resistant group according to the tumor response to paclitaxel-based chemotherapy after surgery, and the incidence of observed and recorded toxic reaction. Polymerase chain reaction-restriction fragment length polymorphism (PCR-RFLP) method was applied to test the polymorphisms of rs2516839 and rs3737787 in USF1 gene after extraction of DNA. The correlation between USF1 gene polymorphisms and paclitaxel-based chemotherapy resistance was analyzed using Logistic regression analysis. Stratified analysis was used to test the incidence of toxic reaction in OC patients. Cox proportional hazard model was adapted to make a multiple-factor survival analysis. Significant differences exhibited in the genotype and the allele frequencies of rs 2516839 between the sensitive and resistant groups, which showed no obvious difference in the genotype and allele frequencies of rs3737787. OC patients carrying the GA+AA genotype had higher incidence of serious toxic reaction than those carrying the GG genotype. Physical status score, tumor type, maximum tumor diameter and rs 2516839 were the independent risk factors for the prognosis of OC patients. Taken together, our results suggest that the rs 2516839 polymorphism in USF1 gene may associate with the efficacy and safety of paclitaxel-based chemotherapy and prognosis in the treatment of OC.
\end{abstract}

Key words: drug resistance, gene polymorphisms, Paclitaxel-based chemotherapy regimen, prognosis, ovarian cancer, rs2516839 (G>A), rs3737787(C>T), USF1 gene

Ovarian cancer (OC), the fourth commonest gynecologic cancer, has been the third leading reason of death caused by gynecologic malignancy among women [1]. OC patients are typically diagnosed at a late stage, with a 5-year survival rate of less than $30 \%$ [2]. Symptoms of OC are indeterminate, including abdominal discomfort, cacochylia, and abdominal distension [3]. The diffuse spread of OC is considered to arise through the peritoneal circulation, related to ascites formation [2].

Since the mid-1990s, maximal surgical debulking combined with platinum-based chemotherapy has been the standard approach in treating advanced OC, which lead to a higher response rate of approximately $75 \%$ in OC patients [4]. However, the rates of palindromia and mortality are still high (5-year survival rate: $20-40 \%$ ) and most patients eventually recrudesce because of drug resistance [5]. Identifying new powerful medication and establishing better chemotherapy regime are extremely urgent. Recently, the chemotherapy based on paclitaxel-platinum, which includes surgical staging and resection, has been identified as one of the universal therapeutic methods in treating advanced epithelial OC [6]. However, 75\% patients eventually relapse with drug resistant disease within 18 months [7].

As one of the most important factors for the treatment of failure or death in patients with OC, the mechanism of paclitaxel resistance is complicated and not yet completely expounded [8]. A study has demonstrated that changes involved in glycolysis (HK1, ADH1A, and ENO3), oxidative stress (MAOA, UGT1A6, and CYBA), mRNA and protein (translation factors and multiple ribosomal genes) synthesis, leukocyte transendothelial migration pathways and glutathione metabolism are the major causes of paclitaxel resistance [9]. Another study reported that paclitaxel resistance identified changes in pathways associated with mRNA and 
protein synthesis, and multiple ribosomal genes (RPS20, RPL26, RPL10A, RPL39, RPL7, and RPL34) and translation factors [7]. Recently, the correlation between the mutation of TEKT4 gene and paclitaxel resistance has been demonstrated [10]. Preventing or delaying the development of paclitaxel resistance may be greatly conductive to improve the clinical outcome of cancer patients.

The Upstream stimulatory factor 1 (USF1) is considered to be one of the ubiquitous transcription factors of the bzHLH (leucine zipper-basic-helix-loop-helix) family [11]. As an important regulator of enormous genes, USF1 is involved in thrombotic complications of the coronary plaque, stress and immune responses, cell cycle and differentiation, and lipid and glucose metabolism [12]. Familial combined hyperlipidemia and one of its component traits had been reported to correlate with USF1 gene polymorphisms in many studies and were also analyzed in the context of diabetes mellitus type II, metabolic syndrome and CAD [13].

Evidence has demonstrated that protein expressions of JAK2, HSP, MSH2, WNT-1 and FZD-1 gene are associated with paclitaxel-based chemotherapy resistance of OC patients [14]. However, little attention has been paid to the relationship between USF1 gene polymorphisms and paclitaxel-based chemotherapy resistance of OC patients. Thus, in this study, we aimed to explore the correlations of the functional SNPs (rs2516839 and rs3737787) in USF1 gene with the efficacy and safety of paclitaxel-based chemotherapy and prognosis in treating patients with OC.

\section{Materials and methods}

Study subjects. Between February 2009 and March 2011, a total of 122 patients (Han nationality, age: 27-78 years, median age: 51 years) diagnosed with $\mathrm{OC}$ and treated in The First Clinical Medical College of China Three Gorges University, were divided into stage II $(n=35)$, stage III $(n=64)$ and stage IV $(n=23)$ (2010) [15]. Pathologic types were categorized into serous cystadenocarcinoma based on the International Federation of Gynecology and Obstetrics (FIGO) staging $(n=68)$, mucinous cystadenocarcinoma $(n=16)$, endometrioid carcinoma $(n=19)$ and other epithelial cancers $(n=19)$. According to the diagnostic criteria recommended by the World Health Organization (WHO) [16], the tumors were classified into well differentiated $(n=63)$, moderately differentiated $(n=38)$, and poorly differentiated $(n=21)$. The inclusion criteria were as follows: (1) Patients pathologically diagnosed as primary OC; (2) OC patients who never received chemotherapy and hormone therapy; (3) OC patients who were continuously treated with paclitaxel-based chemotherapy for at least 6 cycles; (4) OC patients with no history of other cancers and concomitant malignant tumor. Importantly, this study was performed with the approval of the Ethics committee of The First Clinical Medical College of China Three Gorges University, which also strictly followed the ethical principles involving human subjects as formulated in the Helsinki Declaration. Informed consent was obtained from every participant or their legal guardians.

Chemotherapy regimens and efficacy evaluation. The chemotherapy regimen was illustrated in a combination of paclitaxel (175 mg/m2, 3-hour intravenous infusion) and carboplatin (AUC=5-7.5) once every 3 weeks for a total of 6-8 cycles. Tumor responses were categorized as complete response $(C R)(n=28)$, partial response $(P R)(n=61)$, stable disease $(S D)(n=25)$, or progressive disease (PD) $(n=8)$ according to the Clinical Curative Effect Criteria for Solid Tumors stipulated by WHO [16], the total response rate $(R R)=C R+P R$. Patients were divided into the sensitive group $(\mathrm{CR}+\mathrm{PR}, \mathrm{n}=89)$ and the resistant group $(\mathrm{SD}+\mathrm{PD}, \mathrm{n}=33)$ according to the curative effect of paclitaxel-based chemotherapy. According to the toxic reaction, all patients with OC were graded (grade $0-4$ ) in strict accordance with the Response Evaluation Criteria in Solid Tumors (RECIST) guidelines of World Health Organization (WHO) [16], including anaphylaxis, peripheral nerve toxicity, vomiting, diarrhea, and aleucocytosis etc.

DNA extraction. After obtaining informed consent, $5 \mathrm{ml}$ of venous blood were taken from patients and put into the EP tube for $15-25$ minutes at $37^{\circ} \mathrm{C}$, oscillated and mixed by adding $1 \mathrm{ml}$ lysate, and centrifuged by $12000 \mathrm{r} / \mathrm{min}$ for 5 minutes after putting in room-temperature for 15 minutes. DNA extraction was carried out with a genomic DNA extraction kit (Promega, US). The concentration $(100 \pm 20 \mathrm{mg} / \mathrm{L})$ of the DNA was assessed using NANODROP2000 (Thermo, Massachusetts, US), and the purity was assessed by the optical density (OD) measurement at $260 \mathrm{~nm}$. The average purity (OD260/OD280) of the samples was required to be between 1.6 and 1.9, and DNA samples were kept frozen at $-20^{\circ} \mathrm{C}$.

Genotyping. Primers were synthesized by Le Jin Biotech (Nanjing) Co., Ltd. For rs2516839, the forward primer was 5'ACGTTGGATGCTGGTCCTTTTTTGGAGGTC-3' and reverse primer was 5'-ACGTTGGATGTCTACCAGGACTTAGCACTC-3' [13]. For rs3737787, the forward primer was 5'ACGTTGGATGAGAGGAGCACAAGGGCCCA-3' and reverse primer was 5'-ACGTTGGATGCAGTGGTGTGAAACACACAA-3' [17]. The experiment procedures were performed using polymerase chain reaction (PCR) kits (Univ Biological Technology Co., Ltd, Shanghai). The PCR reaction system was set up in a total volume of $20 \mu \mathrm{L}$ with a mixture of $1 \mu \mathrm{L}$ DNA samples, $1 \mu \mathrm{L}$ forward primer $(10 \mathrm{pmol} / \mathrm{ml})$, $1 \mu \mathrm{L}$ reverse primer $(10 \mathrm{pmol} / \mathrm{ml}), 7 \mu \mathrm{L}$ deionized water and $10 \mu \mathrm{L}$ PCR. The PCR reaction conditions were arranged as follows: pre-denaturalization at $95^{\circ} \mathrm{C}$ for 5 minutes; then 35 cycles of denaturalization for 1 minute at $95^{\circ} \mathrm{C}$, anneal at $65^{\circ} \mathrm{C}$ for 30 seconds, extension at $72^{\circ} \mathrm{C}$ for 1 minute; and the final step was elongation for 10 minutes at $72^{\circ} \mathrm{C}$. In the reaction mixtures $4 \mu \mathrm{L}$ of amplification products and $1 \mu \mathrm{L}$ of bromophenol blue solution were added, which then were subjected to electrophoresis in 3\% agarose gel. Running time in $0.5 \times$ TBE buffer was 15 minutes $(75 \mathrm{~V})$ and amplification band was visualized under UV light. PCR-amplified products 
of rs2516839 and rs3737787 were digested with restriction enzymes NCOI at $50^{\circ} \mathrm{C}$ and NlaIII at $37^{\circ} \mathrm{C}$ (NEB Company, US, Beijing branch). Digestion products were resolved by electrophoresis on a $3 \%$ agarose gels $(110 \mathrm{~V}, 40 \mathrm{~min})$ and visualized under UV light. Ten percent of PCR products were randomly selected and sent to Shanghai Sangon Biological Engineering Technology Co., Ltd and the results of polymerase chain reaction-restriction fragment length polymorphism (PCR-RFLP) were verified by completely sequencing the PCR products from both directions.

Follow-up. A regular follow-up of 1 5 years for 100 OC patients (follow-up rate $88.52 \%$ ) was performed by outpatient service, return visit, follow-up letters and telephone interview, including the results of last examination, gynecological examination, imaging examination, tumor markers examination and physical status score etc. The overall 1-year, 3 -year and 5-year survival rate was $88.89 \%, 69.44 \%$ and $37.96 \%$. Follow-up start time was defined as the first month after treatment. Follow-up appointments were scheduled once in 3 months within the first year and 1-2 times per year later until the occurrence of death.

Statistical analysis. SPSS 20.0 integrated software (SPSS Inc. IBM, Chicago, IL, USA) was applied for the statistical analysis. Continuous data was shown as mean \pm standard deviation $( \pm s)$. The t-test was used for the comparison of two groups, and one-way analysis of variance (ANOVA) for comparison among multi-group. Welch's t-test was explored for the data that did not meet the assumption of equal variances. Pairwise comparisons were performed using the Least Significant Difference (LSD) test (for homogeneity of variance) or Tamhane's test (for heterogeneity of variance). The differences in genotype and allele frequencies among groups were identified using Pearson's Chi square test. Logistic regression analysis was conducted for the relationship between USF1 gene polymorphisms and paclitaxelbased chemotherapy resistance. Hardy-Weinberg equilibrium was measured by the chi-square test. Survival was calculated by the Kaplan-Meier (KM) method and the Cox proportional hazard model was adapted to make a multiplefactor analysis. All statistical tests were two-sided, with $\mathrm{p}<0.05$ being considered statistically significant.

\section{Results}

Baseline characteristics of OC patients between the sensitive and resistant groups. A total of 122 OC patients were categorized into a sensitive group $(n=89$; mean age: $51.4 \pm 12.9$ years; mean weight: $54.1 \pm 8.9 \mathrm{~kg}$ ) and a resistant group $(n=33$; mean age: $53.6 \pm 12.2$ years; mean weight: $53.0 \pm 7.7 \mathrm{~kg}$ ). As shown in Table 1, the baseline characteristics of the 122 patients revealed that no significant difference existed in the age and weight between the sensitive and resistant groups (all $\mathrm{p}>0.05$ ). Physical status score, FIGO stage, pathologic types and maximum tumor diameter also exhibited no notable difference between these two groups (all $\mathrm{p}>0.05$ ).
The incidences of toxic reaction in OC patients between the sensitive and resistant groups. After the treatment of paclitaxel-based chemotherapy, no toxicity-related death was found in the sensitive and resistant groups, while the severe toxic reactions with the highest incidence (grade 3-4) were observed. There were 32 cases of anaphylaxis, 35 cases of peripheral nerve toxicity, 33 cases of vomiting, 38 cases of diarrhea and 37 cases of aleucocytosis in the two groups, while no significant difference in the incidence of the toxic reactions was identified between the sensitive and the resistant group ( $\mathrm{p}>0.05)$ (Table 2).

Table 1. Baseline characteristics of OC patients between the sensitive and resistant groups.

\begin{tabular}{|c|c|c|c|}
\hline Baseline characteristics & $\begin{array}{c}\text { Resistant } \\
\text { group } \\
(\mathbf{n}=33)\end{array}$ & $\begin{array}{c}\text { Sensitive } \\
\text { group } \\
(n=89)\end{array}$ & p-value \\
\hline \multicolumn{4}{|l|}{ Age (years) } \\
\hline$<45$ & 6 & 19 & 0.890 \\
\hline $45-60$ & 13 & 36 & \\
\hline$>60$ & 14 & 34 & \\
\hline Mean weight(kg) & $53.0 \pm 7.7$ & $54.1 \pm 8.9$ & 0.531 \\
\hline \multicolumn{4}{|l|}{ Physical status } \\
\hline $0-1$ point & 24 & 74 & 0.156 \\
\hline 2 points & 9 & 15 & \\
\hline \multicolumn{4}{|l|}{ Pathologic types } \\
\hline Serous adenocarcinoma & 13 & 55 & 0.133 \\
\hline Endometrioid carcinoma & 9 & 10 & \\
\hline Clear-cell carcinoma & 3 & 9 & \\
\hline Mucinous adenocarcinoma & 6 & 10 & \\
\hline Undifferentiated carcinoma & 2 & 5 & \\
\hline \multicolumn{4}{|c|}{ Maximum tumor diameter $(\mathrm{cm})$} \\
\hline$<1$ & 12 & 42 & 0.520 \\
\hline $1-2$ & 14 & 29 & \\
\hline$>2$ & 7 & 18 & \\
\hline \multicolumn{4}{|l|}{ Tumor stage } \\
\hline II & 7 & 28 & 0.274 \\
\hline III & 17 & 47 & \\
\hline IV & 9 & 14 & \\
\hline
\end{tabular}

Table 2. The incidences of toxic reaction in OC patients between the sensitive and resistant groups.

\begin{tabular}{lccc}
\hline Toxic reaction & $\begin{array}{c}\text { Resistant } \\
\text { group } \\
(\mathbf{n = 3 3})\end{array}$ & $\begin{array}{c}\text { Sensitive } \\
\text { group } \\
(\mathbf{n}=\mathbf{8 9})\end{array}$ & p-value \\
\hline $\begin{array}{l}\text { Anaphylaxis } \\
(0-2 / 3-4)\end{array}$ & $3 / 12$ & $10 / 20$ & 0.492 \\
$\begin{array}{l}\text { Peripheral nerve toxicity } \\
(0-2 / 3-4)\end{array}$ & $2 / 16$ & $9 / 18$ & 0.656 \\
$\begin{array}{l}\text { Vomiting } \\
(0-2 / 3-4)\end{array}$ & $1 / 4$ & $9 / 19$ & 0.586 \\
$\begin{array}{l}\text { Diarrhea } \\
(0-2 / 3-4)\end{array}$ & $3 / 8$ & $9 / 18$ & 0.715 \\
$\begin{array}{l}\text { Aleucocytosis } \\
(0-2 / 3-4)\end{array}$ & $6 / 7$ & $5 / 19$ & 0.108 \\
\hline
\end{tabular}


The distribution of the allele and genotype frequencies of USF1 gene polymorphisms. The allele frequencies of the rs2516839 and rs3737787 in USF1 gene were in a state of equilibrium according to the Hardy-Weinberg equilibrium and the population was well represented by samples. As shown in Table 3, the distribution of allele and genotype frequencies of rs 2516839 were significantly different between the sensitive and resistant groups (both $\mathrm{p}<0.05$ ), thus the rs2516839 polymorphisms in USF1 gene might be associated with increase of paclitaxel resistance of OC (GA vs. $\mathrm{GG}, \mathrm{OR}=2.246,95 \% \mathrm{CI}=1.252-4.028, \mathrm{p}<0.05$; $\mathrm{AA}$ vs. $\mathrm{GG}$, $\mathrm{OR}=2.246,95 \% \mathrm{CI}=1.252-4.028, \mathrm{p}<0.05 ; \mathrm{GA}+\mathrm{AA}$ vs. $\mathrm{GG}$, $\mathrm{OR}=2.246,95 \% \mathrm{CI}=1.252-4.028, \mathrm{p}<0.05 ; \mathrm{A}$ vs. $\mathrm{G}, \mathrm{OR}=7.768$, $95 \% \mathrm{CI}=1.147-2.725, \mathrm{p}<0.05)$. However, there was no evident difference in terms of the genotype and allele frequencies of the rs3737787 between the sensitive and resistant groups (all $\mathrm{p}>0.05$ ).

Correlations between the USF1 genepolymorphisms and the clinicopathological features of OC patients. As shown in Table 4, stratified analysis of clinical data (age, mean age and mean weight) was performed, indicating that there was no statistical significance in the difference between frequencies of GG genotype and GA+AA genotype of rs2516839 in USF1 gene ( $p>0.05)$. Based on the stratified analysis of physical status score, tumor pathology and maximum tumor diameter, the frequencies of the GG genotype of rs2516839 was notably different with the GA+AA genotype $(\mathrm{p}<0.05)$. Compared with the patients with a physical status score of 2 points and maximum tumor diameter less than or equal to 2 $\mathrm{cm}$, the frequencies of GA+AA genotype among OC patients with a physical status score of $0-1$ point and maximum tumor diameter larger than $2 \mathrm{~cm}$ was significantly higher, the proportion of patients with ovarian serous adenocarcinomas in OC patients carrying the GG genotype was notably increased $(p<0.05)$. However, there was no significant differ- ence in the frequencies between the CC genotype and CT+TT genotype of rs3737787 in USF1 gene according to the stratified analysis of age, mean age, mean weight, physical status score, pathological type of tumors and maximum tumor diameter $(\mathrm{p}>0.05)$.

Associations of the USF1 gene polymorphisms with the incidence of toxic reactions among OC patients. As can be seen in Table 5, a total of 122 OC patients were stratified based on the toxic reactions to paclitaxel-based chemotherapy. Grade 3-4 was regarded as severe toxic reaction. The incidences of the serious toxic reactions in patients carrying GA+AA genotype of rs2516839 in USF1 gene were obviously higher than in the patients carrying GG genotype $(\mathrm{p}<0.05)$. There was no significant difference between the frequencies of the distribution of CC genotype and CT + TT genotype of rs3737787 in USF1 gene based on the stratified analysis of anaphylaxis, peripheral nerve toxicity, vomiting, diarrhea and aleucocytosis $(\mathrm{p}>0.05)$.

Relationship between the USF1 gene polymorphism and prognosis of $\mathrm{OC}$ patients. The results based on KaplanMeier curves (Figures 1 and 2) indicated that the 5-year cumulative survival rates of the OC patients were $37.96 \%$, while the cumulative survival rates of OC patients carrying GG and GA+AA genotype were $55.32 \%$ and $20.00 \%$ respectively. The difference in the cumulative survival rates of the OC patients carrying GG genotype and OC patients carrying $\mathrm{GA}+\mathrm{AA}$ genotype was statistically significant $(\mathrm{p}<0.05)$. The results of the Cox multiple regression analysis revealed that the physical status score $(\mathrm{OR}=1.909)$, tumor pathology $(\mathrm{OR}=2.650)$, maximum tumor diameter $(\mathrm{OR}=1.729)$ and rs2516839 $(\mathrm{OR}=1.729)$ were independent risk factors for the prognosis of OC patients. Physical status score (2 points), maximum tumor diameter (larger than $2 \mathrm{~cm}$ ), serous adenocarcinoma and GA+AA genotype of rs 2516839 were the risk factors for prognosis of OC patients (all $\mathrm{p}<0.05$ ) (Table 6).

Table 3. The distribution of allele and genotype frequencies of USF1 gene polymorphisms.

\begin{tabular}{|c|c|c|c|c|c|}
\hline SNPs & $\begin{array}{l}\text { Resistant group } \\
(\mathbf{n}=33)\end{array}$ & $\begin{array}{c}\text { Sensitive group } \\
(\mathbf{n}=89)\end{array}$ & p-value & OR & $95 \% \mathrm{CI}$ \\
\hline \multicolumn{6}{|c|}{ rs2516839 (G>A) } \\
\hline GG & $7(21.2 \%)$ & $40(44.9 \%)$ & & & Reference \\
\hline GA & $8(24.2 \%)$ & $13(14.6 \%)$ & 0.033 & 3.516 & $1.068-11.580$ \\
\hline AA & $18(54.5 \%)$ & $36(40.4 \%)$ & 0.015 & 3.420 & $1.220-9.540$ \\
\hline $\mathrm{GA}+\mathrm{AA}$ & $26(78.8 \%)$ & $49(55.1 \%)$ & 0.005 & 3.840 & $1.450-10.200$ \\
\hline G allele & $22(33.3 \%)$ & $93(52.2 \%)$ & & & Reference \\
\hline A allele & $44(66.7 \%)$ & $85(47.8 \%)$ & 0.007 & 2.240 & $1.240-4.050$ \\
\hline \multicolumn{6}{|c|}{ rs3737787 (C>T) } \\
\hline $\mathrm{CC}$ & $17(51.5 \%)$ & $43(48.3 \%)$ & & & Reference \\
\hline $\mathrm{CT}$ & $10(30.3 \%)$ & $28(31.5 \%)$ & 0.828 & 1.107 & $0.443-2.764$ \\
\hline $\mathrm{TT}$ & $6(18.2 \%)$ & $18(20.2 \%)$ & 0.757 & 1.186 & $0.402-3.498$ \\
\hline $\mathrm{CT}+\mathrm{TT}$ & $16(48.5 \%)$ & $46(51.7 \%)$ & 0.753 & 1.137 & $0.511-2.528$ \\
\hline $\mathrm{C}$ allele & $44(66.7 \%)$ & $114(64.0 \%)$ & & & Reference \\
\hline $\mathrm{T}$ allele & $22(33.3 \%)$ & $64(36.0 \%)$ & 0.703 & 1.123 & $0.618-2.039$ \\
\hline
\end{tabular}

Note: SNPs, functional single nucleotide polymorphisms; 
Table 4. Correlation between the USF1 gene polymorphisms and the clinicopathological features of OC patients.

\begin{tabular}{|c|c|c|c|c|c|c|c|c|c|c|}
\hline \multirow{2}{*}{ Clinical features } & \multicolumn{2}{|c|}{ rs2516839 $(\mathrm{G}>\mathrm{A})$} & \multirow{2}{*}{ p-value } & \multirow{2}{*}{ OR } & \multirow{2}{*}{$95 \% \mathrm{CI}$} & \multicolumn{2}{|c|}{ rs3737787 $(\mathrm{C}>\mathrm{T})$} & \multirow{2}{*}{ p-value } & \multirow{2}{*}{ OR } & \multirow{2}{*}{$95 \% \mathrm{CI}$} \\
\hline & GG & GA+AA & & & & $\mathrm{CT}+\mathrm{TT}$ & $\mathrm{CC}$ & & & \\
\hline \multicolumn{11}{|l|}{ Age (years) } \\
\hline$<45$ & $9(19.1 \%)$ & $16(21.3 \%)$ & 0.846 & 0.873 & $0.351-2.176$ & $12(19.4 \%)$ & $13(21.7 \%)$ & 0.741 & 0.867 & $0.360-2.092$ \\
\hline $45-60$ & $18(38.3 \%)$ & $31(41.3 \%)$ & & & & $27(43.5 \%)$ & $22(36.7 \%)$ & & & \\
\hline$>60$ & $20(42.6 \%)$ & $28(37.3 \%)$ & & & & $23(37.1 \%)$ & $25(41.7 \%)$ & & & \\
\hline Mean weight (kg) & $54.7 \pm 8.8$ & $53.2 \pm 8.3$ & 0.344 & 1.010 & $1.020-1.330$ & $53.0 \pm 8.7$ & $54.6 \pm 8.3$ & 0.301 & 1.21 & $0.75-1.50$ \\
\hline \multicolumn{11}{|l|}{ Physical } \\
\hline \multicolumn{11}{|l|}{ Status score } \\
\hline $0-1$ & $31(66.0 \%)$ & $67(89.3 \%)$ & 0.002 & 4.323 & $1.672-11.170$ & $44(71.0 \%)$ & $54(90.0 \%)$ & 0.083 & 0.442 & $0.173-1.129$ \\
\hline 2 & $16(34.0 \%)$ & $8(10.7 \%)$ & & & & $18(29.0 \%)$ & $6(10.0 \%)$ & & & \\
\hline \multicolumn{11}{|l|}{ Pathology } \\
\hline Serous adeno carcinoma & $30(63.8 \%)$ & $38(50.7 \%)$ & 0.030 & 1.718 & $0.813-3.630$ & $34(54.8 \%)$ & $34(56.7 \%)$ & 0.429 & 0.929 & $0.454-1.898$ \\
\hline Endometrioid carcinoma & $11(25.5 \%)$ & $8(10.7 \%)$ & & & & $8(12.9 \%)$ & $11(18.3 \%)$ & & & \\
\hline Clear-cell carcinoma & $2(4.3 \%)$ & $10(13.3 \%)$ & & & & $9(14.5 \%)$ & $3(5.0 \%)$ & & & \\
\hline Mucinous adeno carcinoma & $3(6.4 \%)$ & $13(17.3 \%)$ & & & & $7(11.3 \%)$ & $9(15.0 \%)$ & & & \\
\hline Undifferentiated carcinoma & $1(2.1 \%)$ & $6(8.0 \%)$ & & & & $4(6.5 \%)$ & $3(5.0 \%)$ & & & \\
\hline \multicolumn{11}{|l|}{ Maximum tumor diameter $(\mathrm{cm})$} \\
\hline$<1$ & $28(59.6 \%)$ & $26(34.7 \%)$ & 0.003 & 2.777 & $1.309-5.893$ & $26(41.9 \%)$ & $28(46.7 \%)$ & 0.718 & 0.825 & $0.404-1.688$ \\
\hline $1-2$ & $8(17.0 \%)$ & $35(46.7 \%)$ & & & & $24(38.7 \%)$ & $19(31.7 \%)$ & & & \\
\hline$>2$ & $11(23.4 \%)$ & $14(18.7 \%)$ & & & & $12(19.4 \%)$ & $13(21.7 \%)$ & & & \\
\hline \multicolumn{11}{|l|}{ Tumor stage } \\
\hline II & $20(42.6 \%)$ & $15(20.0 \%)$ & 0.016 & 2.960 & $1.320-6.660$ & $16(25.8 \%)$ & $19(31.7 \%)$ & 0.772 & 0.7506 & $0.342-1.650$ \\
\hline III & $22(46.8 \%)$ & $42(56.0 \%)$ & & & & $34(54.8 \%)$ & $30(50.0 \%)$ & & & \\
\hline IV & $5(10.6 \%)$ & $18(24.0 \%)$ & & & & $12(19.4 \%)$ & $11(18.3 \%)$ & & & \\
\hline
\end{tabular}

Table 5. Association of the USF1 gene polymorphisms with the incidence of toxic reactions among OC patients.

\begin{tabular}{|c|c|c|c|c|c|c|c|c|c|c|}
\hline \multirow{2}{*}{ Toxic reactions } & \multicolumn{2}{|c|}{$\operatorname{rs} 2516839(\mathrm{G}>\mathrm{A})$} & \multirow{2}{*}{ p-value } & \multirow{2}{*}{ OR } & \multirow{2}{*}{$95 \% \mathrm{CI}$} & \multicolumn{2}{|c|}{ rs3737787 $(\mathrm{C}>\mathrm{T})$} & \multirow{2}{*}{ p-value } & \multirow{2}{*}{ OR } & \multirow{2}{*}{$95 \% \mathrm{CI}$} \\
\hline & GG & $\mathbf{G A}+\mathbf{A A}$ & & & & $\mathrm{CT}+\mathrm{TT}$ & $\mathrm{CC}$ & & & \\
\hline \multicolumn{11}{|l|}{ Anaphylaxis } \\
\hline \multirow[t]{2}{*}{$0-2$} & $8(47.1 \%)$ & $5(17.9 \%)$ & 0.036 & 4.089 & $1.052-15.890$ & $6(30.0 \%)$ & 7 (28.0\%) & 0.883 & 1.102 & $0.3018-4.025$ \\
\hline & $9(52.9 \%)$ & $23(82.1 \%)$ & & & & $14(70.0 \%)$ & $18(72.0 \%)$ & & & \\
\hline \multicolumn{11}{|c|}{ Peripheral nerve toxicity } \\
\hline \multirow[t]{2}{*}{$0-2$} & $6(60.0 \%)$ & $5(20.0 \%)$ & 0.021 & 6.000 & $1.211-29.740$ & $8(47.1 \%)$ & $3(16.7 \%)$ & 0.053 & 4.440 & $0.931-21.230$ \\
\hline & $4(40.0 \%)$ & $20(80.0 \%)$ & & & & $9(52.9 \%)$ & $15(83.3 \%)$ & & & \\
\hline \multicolumn{11}{|l|}{ Vomiting } \\
\hline \multirow[t]{2}{*}{$0-2$} & $7(58.3 \%)$ & $3(14.3 \%)$ & 0.008 & 8.400 & $1.570-44.900$ & $4(21.1 \%)$ & $6(42.9 \%)$ & 0.180 & 0.356 & $0.077-1.640$ \\
\hline & $5(41.7 \%)$ & $18(85.7 \%)$ & & & & $15(78.9 \%)$ & $8(57.1 \%)$ & & & \\
\hline \multicolumn{11}{|l|}{ Diarrhea } \\
\hline \multirow[t]{2}{*}{$0-2$} & $8(57.1 \%)$ & $4(16.7 \%)$ & 0.010 & 6.667 & $1.476-30.120$ & $7(38.9 \%)$ & $5(25.0 \%)$ & 0.358 & 1.909 & $0.477-7.641$ \\
\hline & $6(42.9 \%)$ & $20(83.3 \%)$ & & & & $11(61.1 \%)$ & $15(75.0 \%)$ & & & \\
\hline \multicolumn{11}{|l|}{ Aleucocytosis } \\
\hline \multirow[t]{2}{*}{$0-2$} & $6(60.0 \%)$ & $5(18.5 \%)$ & 0.014 & 6.600 & $1.339-32.530$ & $4(19.0 \%)$ & $7(43.8 \%)$ & 0.103 & 0.302 & $0.070-1.317$ \\
\hline & $4(40.0 \%)$ & $22(81.5 \%)$ & & & & $17(81.0 \%)$ & $9(56.3 \%)$ & & & \\
\hline
\end{tabular}

\section{Discussion}

This study explored the correlation of USF1 gene polymorphisms with the efficacy and safety of paclitaxelbased chemotherapy and prognosis in the treatment of OC, and the results indicate that the rs 2516839 polymorphisms in USF1 gene might have an association with the increase of paclitaxel resistance of OC, which was firstly proposed. The Logistic regression analysis has presented that there was a significant difference in the genotype and allele frequencies of rs2516839 between the sensitive and resistant groups and no obvious difference in the genotypes and allele frequencies of rs3737787 was found between these two groups. In the previous study, it has been demonstrated that TEKT4 
Table 6. Relationship between the USF1 gene polymorphism and the prognosis of OC patients.

\begin{tabular}{lccccc}
\hline Variable & Regression coefficient (B) & Standard error & p-value & OR & 95\%CI \\
\hline rs2516839(G)A $)$ & 0.975 & 0.302 & 0.001 & 2.652 & $1.466-4.797$ \\
Pathology & 0.275 & 0.111 & 0.013 & 1.317 & $1.060-1.635$ \\
Physical status score & 0.756 & 0.290 & 0.009 & 2.129 & $1.205-3.761$ \\
Maximum tumor diameter & 0.442 & 0.152 & 0.004 & 1.555 & $1.156-2.094$ \\
\hline
\end{tabular}

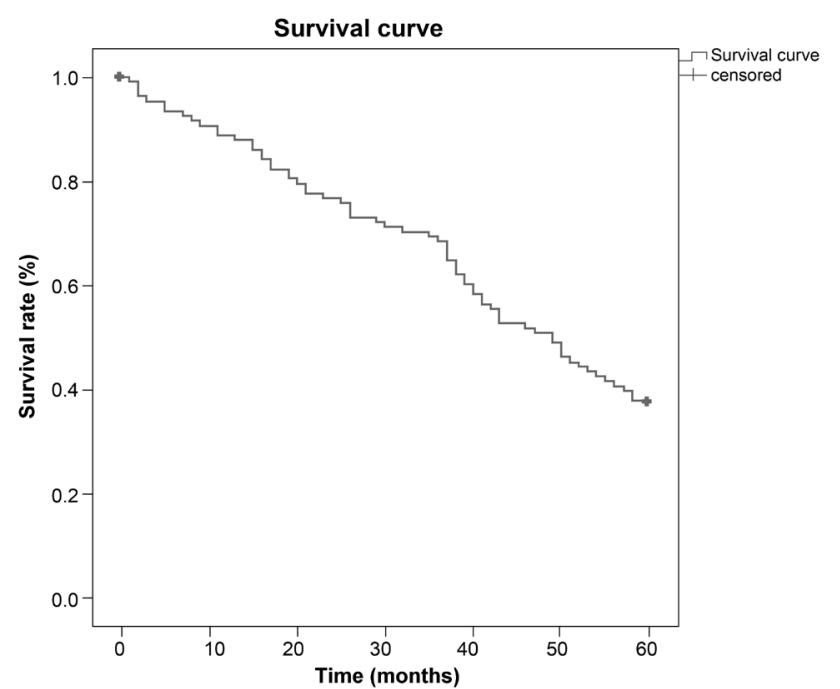

Figure 1. Kaplan-Meier curves of cumulative survival rates of $100 \mathrm{OC}$ patients.

gene could cause a poorer response and survival of patients treated with paclitaxel-based neoadjuvant chemotherapy [10]. It has also been reported that the rs 2516838 polymorphisms dominant model and allelic model were protective factors in papillary thyroid cancer [17]. And other results indicated that the SNP of rs2516839 was closely correlated with the increased risk of hepatocellular carcinoma [18].

According to Cox multiple regression analysis, our study demonstrates that USF1 gene affects the prognosis of OC patients and rs2516839 in USF1 gene is one of the independent risk factors for the prognosis of OC patients. Physical status score, tumor pathology, and maximum tumor diameter were also independent risk factors for the prognosis of OC patients. And physical status score (2 points), maximum tumor diameter (larger than $2 \mathrm{~cm}$ ), serous adenocarcinoma and GA+AA carriers at rs2516839 were risk factors for the prognosis of OC patients. This was the first study about the association between USF1 and prognosis of OC patients. Former study had suggested that stage at diagnosis, maximum residual disease following cytoreductive surgery, and performance status were the three major prognostic factors of OC [19]. Besides, it has been defined that the expression of $G$ protein-coupled receptor 56, size of residual tumor at the end of primary

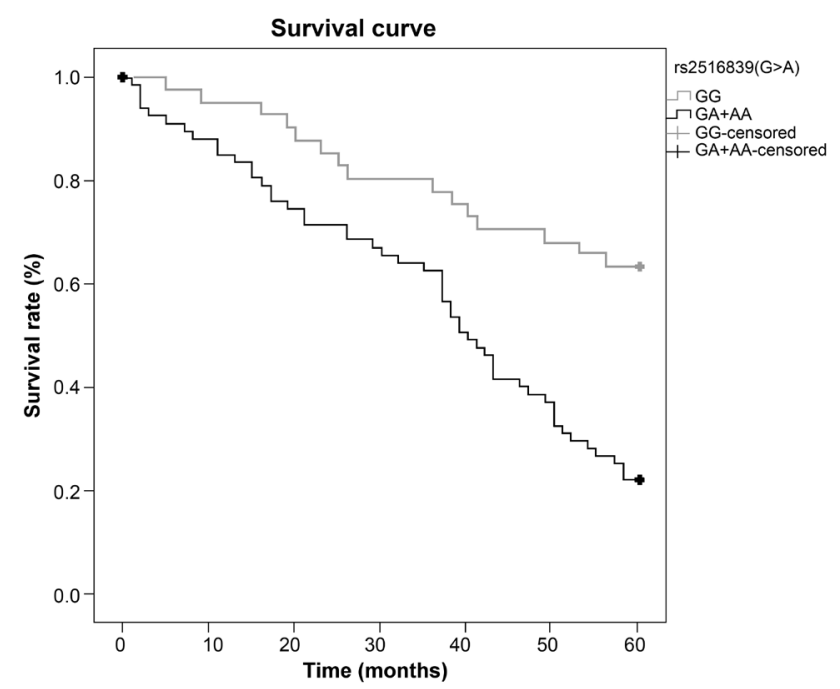

Figure 2. Kaplan-Meier curves of OC patients carrying different genotypes of rs2516839 in USF1 gene.

surgery and age at diagnosis were independent prognostic factors in OC [20, 21]. Moreover, it also has been reported that age, performance status, tumor histology, optimal cytoreduction, and chemotherapy were key prognostic factors for OC patients. [4].

With regard to the safety of paclitaxel-based chemotherapy, no toxicity-related death was found. There was no significant difference in toxic reaction of OC patients between the sensitive and resistant groups. Furthermore, stratified analysis to 100 OC patients showed that the incidences of serious toxic reactions in patients carrying GA+AA genotype of rs2516839 in USF1 gene were significantly higher than in the patients carrying GG genotype $(\mathrm{p}<0.05)$. It has been reported that no cancer-free patient has developed late bowel toxicity >CTC 2 in the study about carboplatin-paclitaxel based chemotherapy for advanced uterine epithelial cancer, and all patients treated with radiotherapy showed no toxicity-related interruptions and no CTCAE grade 4 toxicities occurred during the carboplatinpaclitaxel based chemotherapy [22]. A study has demonstrated that the albumin-bound paclitaxel-based chemotherapy is safe and efficient in the operation for patients with advanced esophageal cancer and no unanticipated treatment or toxicity-related deaths were observed [23]. What's more, 
there emerged a variety of new drugs on the safety and efficacy of the treatment of cerebral ischemia and cancer has sought more and further investigations in future study, such as 3-n-Butylphthalide (NBP) and Famitinib, which were well absorbed and extensively metabolized by multiple enzymes to various metabolites prior to urinary excretions [24, 25].

In summary, our preliminary findings suggest that the rs2516839 polymorphism in USF1 gene might associate with the efficacy and safety of paclitaxel-based chemotherapy and prognosis in treating OC, which provides a new idea and new way in the operation of OC patients. However, there were a few limitations in the present study such as a trial size in the designed experiment, which was relatively small and gene-gene or gene-environment interactions which may influence the results. It must be noted that our findings need to be further validated by more specific studies with larger samples, more advanced gene technologies and well-designed chemotherapy. We will extend the time period of our study to involve more subjects and further study the correlation of rs 2516839 polymorphism in USF1 gene with the efficacy and safety of paclitaxel-based chemotherapy and prognosis in the treatment of OC.

Acknowledgments: This study was supported by "The role and mechanism of Nampt in ovarian cancer cells and tumor bearing mice" (2014CFB687). We would like to acknowledge the helpful comments on this paper received from our reviewers.

\section{References}

[1] TANGJITGAMOL S, MANUSIRIVITHAYA S, LAOPAIBOON M, LUMBIGANON P, BRYANT A. Interval debulking surgery for advanced epithelial ovarian cancer. Cochrane Database Syst Rev 2013; CD006014. doi: 10.1002/14651858. CD006014.pub6

[2] YEUNG TL, LEUNG CS, YIP KP, AU YEUNG CL, WONG ST et al. Cellular and molecular processes in ovarian cancer metastasis. A Review in the Theme: Cell and Molecular Processes in Cancer Metastasis. Am J Physiol Cell Physiol 2015; 309: C444-456. doi: 10.1152/ajpcell.00188.2015

[3] ARAVANTINOS G, PECTASIDES D. Bevacizumab in combination with chemotherapy for the treatment of advanced ovarian cancer: a systematic review. J Ovarian Res 2014; 7: 57. doi: 10.1186/1757-2215-7-57

[4] AI B, BIE Z, ZHANG S, LI A. Paclitaxel targets VEGF-mediated angiogenesis in ovarian cancer treatment. Am J Cancer Res 2016; 6: 1624-1635.

[5] QIAN X, QIN J, PAN S, LI X, PAN Y et al. Maintenance Therapy in Ovarian Cancer with Targeted Agents Improves PFS and OS: A Systematic Review and Meta-Analysis. PLoS One 2015; 10: e0139026. doi: 10.1371/journal.pone.0139026

[6] GAO Y, LIU Z, CHEN X, LUO W, ZHANG L et al. Intraoperative radiotherapy electron boost in advanced and recurrent epithelial ovarian carcinoma: a retrospective study. BMC Cancer 2011; 11: 439. doi: 10.1186/1471-2407-11-439
[7] SHERMAN-BAUST CA, BECKER KG, WOOD III WH, ZHANG Y, MORIN PJ. Gene expression and pathway analysis of ovarian cancer cells selected for resistance to cisplatin, paclitaxel, or doxorubicin. J Ovarian Res 2011; 4: 21. doi: $\underline{10.1186 / 1757-2215-4-21}$

[8] FU Y, HU D, QIU J, XIE X, YE F et al. Overexpression of glycogen synthase kinase-3 in ovarian carcinoma cells with acquired paclitaxel resistance. Int J Gynecol Cancer 2011; 21: 439-444. doi: 10.1097/IGC.0b013e31820d7366

[9] KAMPAN NC, MADONDO MT, MCNALLY OM, QUINN M, PLEBANSKI M. Paclitaxel and Its Evolving Role in the Management of Ovarian Cancer. Biomed Res Int 2015; 2015: 413076. doi: 10.1155/2015/413076

[10] JIANG YZ, YU KD, PENG WT, DI GH, WU J et al. Enriched variations in TEKT4 and breast cancer resistance to paclitaxel. Nat Commun 2014; 5: 3802. doi: 10.1038/ncomms4802

[11] CHEUNG E, MAYR P, CODA-ZABETTA F, WOODMAN PG, BOAM DS. DNA-binding activity of the transcription factor upstream stimulatory factor 1 (USF-1) is regulated by cyclin-dependent phosphorylation. Biochem J 1999; $344 \mathrm{Pt}$ 1: $145-152$.

[12] WANG RM, LIU ZZ, GONG YH, CHEN LJ, JIA Q et al. Association analysis of USF1 gene polymorphisms and total unstable carotid plaque area in atherosclerotic stroke patients. J Thromb Thrombolysis 2013; 36: 317-323. doi: 10.1007/s11239-012-0861-0

[13] NIEMIEC P, NOWAK T, IWANICKI T, GORCZYNSKAKOSIORZ S, BALCERZYK A et al. The rs2516839 Polymorphism of the USF1 Gene May Modulate Serum Triglyceride Levels in Response to Cigarette Smoking. Int J Mol Sci 2015; 16: 13203-13216. doi: 10.3390/ijms160613203

[14] LI HX. [Expression of COP9, JAK2, HSP and NADH in ovarian carcinoma tissues after taxol-chemotherapy and their significance]. Zhonghua Fu Chan Ke Za Zhi 2008; 43: 528-532.

[15] SAIDA T, TANAKA YO, MATSUMOTO K, SATOH T, YOSHIKAWA H et al. Revised FIGO staging system for cancer of the ovary, fallopian tube, and peritoneum: important implications for radiologists. Jpn J Radiol 2016; 34: 117-124. doi: $10.1007 / \mathrm{s} 11604-015-0513-3$

[16] SASAKI T. [New guidelines to evaluate the response to treatment "RECIST"]. Gan To Kagaku Ryoho 2000; 27: 21792184.

[17] YUAN Q, BU Q, LI G, ZHANG J, CUI T et al. Association between single nucleotide polymorphisms of upstream transcription factor 1 (USF1) and susceptibility to papillary thyroid cancer. Clin Endocrinol (Oxf) 2016; 84: 564-570. doi: $10.1111 / \mathrm{cen} .12832$

[18] ZHAO X, WANG T, LIU B, WU Z, YU S et al. Significant association between upstream transcription factor 1 rs 2516839 polymorphism and hepatocellular carcinoma risk: a casecontrol study. Tumour Biol 2015; 36: 2551-2558. doi: 10.1007/s13277-014-2871-3

[19] HOLSCHNEIDER CH, BEREK JS. Ovarian cancer: epidemiology, biology, and prognostic factors. Semin Surg Oncol 2000; 19: 3-10.

[20] LIU Z, HUANG Z, YANG W, LI Z, XING S et al. Expression of orphan GPR56 correlates with tumor progression in human epithelial ovarian cancer. Neoplasma 2017; 64: 32-39. doi: 10.4149/neo $2017 \quad 104$ 
[21] TINGULSTAD S, SKJELDESTAD FE, HALVORSEN TB, HAGEN B. Survival and prognostic factors in patients with ovarian cancer. Obstet Gynecol 2003; 101: 885-891.

[22] ROCHET N, KAHN RS, NIEMIERKO A, DELANEY TF, RUSSELL AH. Consolidation whole abdomen irradiation following adjuvant carboplatin-paclitaxel based chemotherapy for advanced uterine epithelial cancer: feasibility, toxicity and outcomes. Radiat Oncol 2013; 8: 236. doi: 10.1186/1748$\underline{717 X-8-236}$

[23] YUAN Y, ZHANG Y, SHI L, MEI JF, FENG JE et al. Clinical Research on Albumin-Bound Paclitaxel-Based Chemotherapy for Advanced Esophageal Cancer. Asian Pac J Cancer Prev 2015; 16: 4993-4996.
[24] DIAO X, DENG P, XIE C, LI X, ZHONG D et al. Metabolism and pharmacokinetics of 3-n-butylphthalide (NBP) in humans: the role of cytochrome P450s and alcohol dehydrogenase in biotransformation. Drug Metab Dispos 2013; 41: 430-444. doi: 10.1124/dmd.112.049684

[25] XIE C, ZHOU J, GUO Z, DIAO X, GAO Z et al. Metabolism and bioactivation of famitinib, a novel inhibitor of receptor tyrosine kinase, in cancer patients. Br J Pharmacol 2013; 168: 1687-1706. doi: 10.1111/bph.12047 